\title{
HOW TECHNOLOGY IS IMPROVING DECISION MAKING FOR ENVIRONMENTAL RESTORATION
}

\author{
John Ditmars, Argonne National Laboratory
}

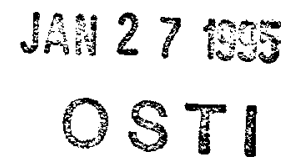

\begin{abstract}
Environmental restoration, or the cleanup of contaminants from past activities, at its core depends on a series of decisions about the nature and extent of contamination, the risk to human health and the environment, and the potential effectiveness of remediation techniques and technologies to reduce the risk to acceptable levels. The effectiveness with which these decisions are made has significant impacts on the cost and duration of the cleanup efforts. The decisions must often be made on the basis of incomplete and uncertain data. Emerging environmental information and data acquisition technologies together with appropriate strategies to support decision making are beginning to change the way environmental restoration occurs in the United States.
\end{abstract}

Past environmental restoration activities too often relied on prescriptive data collection activities to generate the information upon which decisions were to be made. Retrospective studies of such activities have shown that, while often data were gathered for the purpose of reducing the risk in decision making, little true reduction in risk was realized and large amounts of resources were consumed. Recent examination of the failures in the United States to achieve many complete cleanups despite the investment of large sums and time points to the inability to have decisions made efficiently. The solution to the problem involves both regulatory change to allow more flexibility in decision-making and the introduction of technology to improve decision making.

This paper reviews the recent assessments made of the cleanup process and application of strategies and technologies to enhance decision-making for cleanup. It provides examples of the new decision approaches and the technologies that have been employed to speed up characterization and to optimize the implementation of remediation.

\section{Introduction}

The cleanup of contaminants from past activities, environmental restoration, has been a major environmental activity in the United States for the past fifteen years. The Comprehensive Environmental Response, Compensation, and Liability Act of 1980 (CERCLA or Superfund) and the Superfund Amendments and Reorganization Act of 1986 (SARA) provided the U.S. Environmental Protection Agency (EPA) with authority and funding to establish cleanup requirements and to cleanup the nation's worst hazardous waste sites. The Corrective Action portions of the Resource Conservation and Recovery Act (RCRA) likewise require the closure and cleanup of waste facilities.

The EPA's National Priorities List (NPL) now contains over 1200 seriously contaminated sites and is projected to grow to about 2100 sites by the year 2000 [GAO, 1992]. In addition there are over 300 sites at federally-owned facilities that have been added to this total. There have been few completed cleanups and less than 50 sites have been removed from the NPL. Estimates of the costs of cleaning up the remaining sites vary widely, but they are all in the hundreds of billions of dollars. Large federal facilities, particularly those related to the defense establishment, have received increasing attention in recent years and now represent a significant portion of the cleanup effort. DHSTRIBUTION OF THIS OOCUMENT IS UMU MTEN

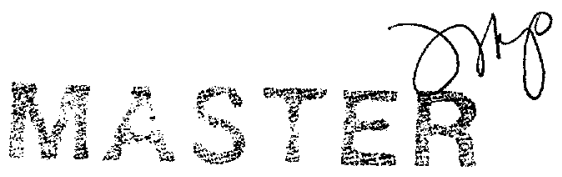




\section{DISCLAIMER}

Portions of this document may be illegible in electronic image products. Images are produced from the best available original document. 
At its core environmental restoration of contaminated sites depends on a series of decisions about the nature and extent of contamination, the risk to human health and the environment, and the potential effectiveness of remediation techniques and technologies to reduce the risk to acceptable levels. The Superfund program in the United States established a series of regulatory steps leading from the discovery of a potential contamination problem to its cleanup. They are designed to provide information for progressive decision making. In simple terms, the steps and their purpose are as follows:

- preliminary assessment

- $\quad$ site inspection

- remedial investigation

- baseline risk assessment

- feasibility study

- public comment

- record of decision

- remedial design

- remedial action review of available information and reconnaissance visit to the site to determine if a release of hazardous substances requires further investigation or action.

collection of samples to describe known contaminants, the surrounding area, and potential human and environmental receptors of contamination.

characterization, through sampling and analyses, of the nature and extent of contamination. It affords sufficient information to support the evaluation of remedial alternatives and remedy selection.

qualitative and quantitative evaluation to define the risk posed to human health and/or the environment by the presence of specific contaminants.

evaluation of alternative remedial actions screened against several technical, cost, and regulatory criteria, leading to selection of a preferred remedy.

community commentary on the selected remedy.

documentation of the final remedy selection.

development of engineering plans and specifications for implementation of remedy.

action construction and implementation of the cleanup.

As logical as the above sequence of activities appears, practice has shown that the "feed forward" requirements for information to support decisions do not work effectively. It is common in practice to find that the data brought forward for decisions at a particular step are inadequate or inappropriate or both. The subsequent return to earlier steps to acquire the necessary data becomes a significant consumer of time and resources. The progressive steps in the cleanup process are geared to be initially open to multiple possibilities and only later to focus by screening out alternative remedies. Practically, it has proved difficult to capture data in early investigations appropriate for all potential forthcoming remedies. "Feedback" mechanisms are needed to focus the information and data acquisition activities of the process -- particularly during the site characterization phase of the remedial investigation step. 
A consequence of the "feed forward" nature of information flow in the Superfund process was the need to establish data quality objectives (DQOs). These were meant to assure that the data were appropriate for decisions at the next step. While early guidelines for the establishment of DQOs were rational and linked to decision making, they were often reduced in practice to simply specification of the level of chemical analysis to be carried out. It also became common to require that the highest level of laboratory chemical analysis quality assurance (following EPA's Contract Laboratory Program procedures) be followed. This was not always a technical expedient but was driven in large measure by the potential of legally imposed penalties on those thought to be responsible for creating the contamination. Thus, "highest quality" chemical analyses were sought not to support technical decisions affecting cleanup but to be acceptable in the legal setting.

There are many reasons why the cleanup process has not been effective. Principal among them is the fact that activities are more focused on the processes and related data acquisition steps than the decisions that they are to support. The drive to gather "enough data" to characterize contamination has not been tempered by the realization that it is usually practically impossible to obtain sufficient data to characterize with complete certainty the nature and extent of contamination. Decision making has, in many cases, been subordinated to data gathering. Consequently, many cleanups have been bogged down in the early steps of the process and have expended considerable resources on problem assessment.

Recognition that these short comings have impeded cleanup has led to the exploration of new approaches to improve the effectiveness and efficiency of cleanup activities in the United States. Part of the impetus has come from federal agencies. They have estimated the potential cost of cleanup of their many installations, and it has become apparent that current practices are very expensive. And, in the case of facility closure actions, present cleanup practices appeared extremely slow and likely to impede the transfer of these facilities for other uses. In addition, for federal facilities the issue of legal responsibility for the cleanup was generally clear -- the federal government would pay for cleanup. Thus, extensive data gathering for the purpose of establishing responsibility for the site cleanup was deemed unnecessary. These considerations have fostered a significant refocusing of strategies for cleanup on those decision processes that have been barriers to actual restoration.

The emphasis on decision making is changing the approach to cleanup. The essential features of these changes are addressed below. They include requirements that data be generated in a timely manner and of adequate quality to support the decisions. Such requirements have led to the introduction of new technologies into the process to:

- generate data rapidly and often at the sites of cleanup studies,

- manage, display, and analyze data efficiently, and

- integrate information to support the decision process for both technical and non-technical decision makers.

\section{Re-examination of the Decision Process for Environmental Restoration}

Several different approaches have been undertaken to streamline the cleanup process in the United States in recent years. They range from modifications in regulatory practice that encourage rapid removals and cleanups where problems are well-established and additional process-driven studies are unnecessary (EPA's Superfund Accelerated Cleanup Model) to early inclusion of stakeholders (regulatory and community members) in the cleanup process. However, re-examinations of the basic relationship between the decisions governing the cleanup 
process and the information upon which the decisions are made have had a profound effect on streamlining efforts.

The re-examination has occurred at several levels of the cleanup process. It can be characterized by two related, but different, approaches -- the "observational approach" and "data quality objectives," aspects of which appear separately, or integrated, in streamlining plans. The observational approach draws upon the well-known principle in geotechnical engineering that uncertainties in subsurface geotechnical properties and characteristics of a site always exist regardless of the degree of site exploration. Prudent engineering therefore requires that some level of uncertainty be accounted for in designs, that contingency plans be prepared for potential deviations from "normal" conditions, that observations be made during construction to detect changes from expectations, and that contingency plans be invoked should deviations from "normal" conditions appear. The subsurface nature of many environmental restoration problems makes the transfer of this principle to restoration problems obviously attractive [Smyth et al., 1992; Wallace and Lincoln, 1989].

More generally, however, the observational approach confronts a fundamental decision issue in the cleanup process -- that the information available is almost always incomplete. It postulates that acknowledgment of those certainties and preparations to deal with unlikely consequences, should they be observed to occur, establish a path forward to cleanup that rational decision makers can follow. It holds out the promise of breaking the loop of never ending data acquisition that plagued past efforts because it removes the goal of eliminating uncertainty in the nature and extent of contamination.

Concomitant with the application of observational approach principles to the cleanup decision process were recent attempts to clarify the concept of data quality objectives as they applied to the cleanup process [Neptune et al., 1990; Ryti and Neptune, 1991; EPA, 1993]. While often viewed as simply a means of defining the level of quality control for chemical analyses of samples of environmental media, DQOs in fact referred to a logical process for planning and designing data acquisition activities that addresses the types, quantity, and quality of data required to support a specific decision. Couched in "total quality" terminology and following standard scientific logic, the DQO approach requires the decision-maker to:

- determine what decision addresses a restoration problem,

- identify the inputs affecting the decision,

- develop a logic statement (quantitative, if possible) relating the inputs to the decision,

- establish the constraints on uncertainty acceptable to stakeholders, and

- optimize the design for obtaining the required data (i.e., minimize resources while satisfying uncertainty constraints).

For example, in application to a contaminated soil problem, the DQO approach can lead to the identification of specific contaminants that are of primary concern because of their contribution to a particular level of human health risk. Depending on the quantitative level of certainty a decision-maker may demand in assessing that risk, there are different requirements for determining the extent of contaminant. Data acquisition schemes for sampling and analyzing soil can be developed to obtain the appropriate quality and quantity of data to meet these requirements -- and no more. The important contribution of the DQO approach to the restoration decision-making process is the rigorous linkage that it establishes between the planning for data acquisition and the decisions that are to be made on the basis of the data. This a priori analysis 
of the potential value of the data is in striking contrast to open-ended data collection that vaguely promises to provide the information needed.

The bias for action in the face of uncertainty of the observational approach and logic appraisal of uncertainty in quantitative terms of the DQO approach were combined to form a strategy for expedient cleanup decision making by the Department of Energy known as the Streamlined Approach For Environmental Restoration (SAFER) [Gianti et al., 1993]. Variants of these approaches are appearing in environmental restoration projects in the United States but most retain these features:

- acknowledgment of the inability of data to provide complete characterization of problems,

- accounting for uncertainty,

- specific linkage of data quantity and quality to the decisions to be made.

An excellent application of these concepts to hydrogeologic decision analysis is given by the work of Freeze and others. [Freeze et al., 1992]. They demonstrate the approach in the design of landfill systems to meet regulatory and other risk constraints in the face of uncertainties regarding subsurface conditions and hydrogeologic transport. Tradeoffs among design costs, monitoring well costs, and the costs of "failure" illustrate clearly the tension between the decision process and the information needed to support decision making.

The author participated recently in the development of a decision strategy to address the problem of the characterization of over 2000 potential release sites at a large federal facility. Many of the sites were thought not to contain serious contamination, but a strategy was necessary to make that determination to the satisfaction of the stakeholders. Resource constraints dictated not undertaking an open-ended characterization at each site. A decision logic was developed that proposed screening action levels of all expected contaminants. These concentrations related to very low values of potential human health risks under conservative exposure scenarios appropriate to the facility. These screening action levels and some existing data from the sites provided data acquisition planners the rules for designing data collection schemes that would permit a rapid initial determination of whether a particular potential release site could be put aside for "no further action" or whether additional characterization was warranted. The data collection designs were sensitive to uncertainty constraints particularly those associated with false negatives. This relatively simple decision strategy holds the possibility of saving significant costs and time by not "over-characterizing" non-problem sites and allows using resources for true problem areas.

The decision-driven data acquisition activities resulting from the re-examination of the cleanup process have highlighted the contributions that technology can make in the implementation of the process.

\section{Application of the Decision Process in the Field}

Execution of accelerated or streamlined approaches to cleanup in the field have taken many forms. A streamlined pilot project at two wood treating sites contaminated with creosote and pentachlorophenol [Sieminski et al., 1993] began by streamlining the planning documents and evaluation procedures. The risk assessments and remedy selection activities were then directed to obvious potential problems as were the field data acquisition activities. Global positioning systems and 48-hour turnaround of analytical results (delivered electronically to the site) reduced the duration of data validation from months to weeks. 
Similarly, a study in Canada faced with a large number of sites with potential mercury contamination in soil developed a decision methodology to guide sampling and to focus cleanup actions [Roffman et al., 1993]. Plans were dynamically adjusted to account for screening results. A screening measurement device to estimate mercury fluxes from soils was developed and employed to drive the characterization. The application of a rigorous decision logic, driven by risk assessments, together with dynamic field screening rapidly focused the study on 15 of 190 possible sites. The field investigation effort was reduced significantly without compromising the overall study objective.

Potential groundwater contamination at landfill sites in New Mexico was investigated efficiently through a characterization program directed toward investigations that would decrease the need for sampling and drilling [Burton, 1992]. Following a strategy similar to that successfully used in petroleum and minerals exploration programs, geological and site history models were generated to guide the selection of multiple surface geophysical techniques. A dynamic, multidisciplinary field approach using these technologies and data interpretation by experienced technical staff on site resulted in significant reductions in time, cost, and intrusive sampling.

While each of the applications summarized above was different with regard to streamlining or expediting some portion of the cleanup process, they and other recent activities in this area share the following characteristics:

- an objective exists to minimize the measurements required to make a defined decision,

- a decision logic, explicit or implicit, is developed before measurements begin to permit dynamic changes in the sampling as the results become available,

- technology is employed that provides data appropriate to the required decision -- often rapid turnaround and in-field screening technologies, and

- data integration or information fusion supports the decision making.

\section{Technologies that Provide Data for Decisions}

The regulatory-driven volume of environmental restoration activity in the United States has grown sufficiently large to have spawned the development of technologies to assist in the rapid and cost-effective acquisition of data. While such technological advances have had positive impacts on portions of the cleanup process, they represent a significant opportunity for improving the decision process. When coupled with decision-based characterization schemes, they have been effective in minimizing oversampling and in limiting investigations to locations where contaminant levels pose real risks to human health or the environment.

The need to understand subsurface conditions has pushed the development of technologies toward rapidly gathering samples from the subsurface, or measuring there, so as to delineate the extent of contamination in soil or groundwater in a relatively short period of time. Direct push, or cone penetrometer, technology has been used successfully in this regard, and holds the potential for other advances. The small diameter penetrations into soil are minimally intrusive and have been used to sample aquifers -- often reducing the need to establish monitoring wells. The flexibility afforded by rapidly sampling at multiple locations in an aquifer permitted characterization of a hexavalent chromium plume that had eluded earlier well sampling [Cherry et al., 1992]. Combining the groundwater sampling capabilities of these devices with field gas chromatograph technologies streamlined the delineation of a 40-acre chlorinated solvent plume 
to within 6 weeks [Prochaska et al., 1991]. Coupling sensors to cone penetrators is an area of continuing development -- with fiber optics and laser-induced fluorescence used to detect petroleum contaminants [Bratton et al., 1993] as just one example of such developments. Multilevel drive point samplers [Widdowson et al.,] have been used to sample soil gas and groundwater as well as to determine aquifer permeability.

Several screening methods for chemical analyses of soil and water have been developed for field use with detection levels and turnaround times that make them appropriate for supporting dynamic decision plans. Immunoassay techniques allow detection of PCBs in soil samples at concentrations below action levels and have contributed to speeding on-site decision making [Mapes, 1991]. Colorometric methods for field screening explosives residues such as TNT, RDX, and 2,4-DNT, in soil and water yield results that compare favorably with those from standard laboratory methods [Jenkins and Walsh, 1992]. These techniques have proved effective in directing more traditional sampling and analysis activities on large installations where potential contamination sites are many. Likewise, hand-held instruments such as X-ray fluorescence devices have been used to locate hot spots of metals contamination as part of a screening decision strategy.

The chemical analysis of samples of environmental media, particularly for organic compounds, has resulted in an industry of commercial laboratories operating under prescribed regulatory quality control and assurance procedures. The time and cost involved in packing and shipping samples to these laboratories and waiting for the results of the analyses to become available for decision making have been identified often as a significant impediment to process.

Consequently, substantial effort has gone into the development of field analytical methods and field, or transportable, gas chromatography/mas spectrometer instruments. A recent critique of the state of such methods and instruments [McDonald et al., 1994] concludes, among other things, that improvements in instrumentation are removing earlier concerns that only expert mass spectrometerists could employ the techniques successfully in the field. It suggests that early integration of the technology into the planning and decision process is essential for the realization of the benefits of on-site data acquisition.

While the development of new sensor and analysis technologies to assist characterization [Wang et al., 1994] enhances the possibilities supporting the decision process even further, there is a cautionary note regarding the infusion of new measurement technologies into the environmental restoration process in the United States. Regulatory agencies have not uniformly accepted the use of field analytical instrumentation. In recent analysis of the adoption of such instrumentation in practice [Moore, 1994], regulatory legislative, and institutional barriers were shown have slowed the implementation of field instrumentation. Strategies to streamline the decision making process have required stakeholder approval, and the means of expediting the availability of data appears to require acceptance as well.

\section{Technologies That Provide Data Integration for Decision Making}

Advances in technologies associated with data acquisition and personal computing systems have made the electronic collection, storage, display, and manipulation of data in the field a practical reality. Systems that acquire and process data from multiple sources are routinely integrated with laptop computers to guide decision making in the field as well as the office.

Most data supporting environmental restoration decision have a spatial, or geographic, reference, and a variety of geographic information systems (GISs) are used to display and integrate information. Traditional GIS database and map layer systems have served to integrate data by overlaying information on topography, contamination contours, groundwater levels, and the like 
to support remedial decision making [Woodside and Otis, 1991]. More recently, GISs with object-oriented databases and vertical dimension capabilities have provided powerful displays data related to subsurface conditions. Some of these systems integrate data of multiple types in rapidly displayed easily queried modes and so that "what if" questions can be posed of complex spatial data sets [McGrath and Brown, 1991]. These systems provide the means to support "observational approach" decision making. Multimedia applications for GIS hold the promise of even more effective displays of decision-related information [Huber, 1994].

While the data integration and display capabilities of GISs are powerful aids to decision making, the analytical capabilities of these systems are generally limited. Several recent efforts have added the capabilities of models or other analytical tools to GIS configurations. For example, simple groundwater transport models have been interfaced with the GIS so as to exploit its display capabilities [Rafai, 1994]. In a more active decision supporting mode, an object-oriented database/GIS has been combined with Bayesian and geostatistical models to assist in sampling decisions [Johnson, 1993a; Johnson, 1993b]. This adaptive sampling model seeks to fuse both "hard" sampling data with related "soft" information on subsurface soil contamination to indicate where additional sampling would have the greatest impact on the uncertainty on plume extent. Retrospective analyses suggest that the model guidance produced significant reductions in the numbers of soil bores and samples required to reach a prescribed level of certainty in the volume of contaminated soil.

Modeling of contaminant transport and fate has historically been a component of the environmental restoration process. However, in many cases the modeling has been carried out by specialists somewhat removed from the data acquisition and decision processes. This role has changed as several factors seem to be bringing modeling more actively into the decision process:

- increased capabilities of modelers to use field data to determine model parameters, particularly in the face of uncertainty and large spatial variability,

- models that predict the performance of remedial technologies, and

- improved visualization capabilities that rapidly reduce complex model results to displays readily grasped by non-technical decision makers and stakeholders.

The coupling of seismic and tracer test data for aquifer property characterization [Hyndman et al., 1994 ] and stochastic approaches to characterizing groundwater contamination [McLaughlin et al., 1993] provide example of how modelers have become integral parts of the data acquisition activities. This is a welcome sign given the importance of the relationship between acceptable levels of uncertainty in model predictions and decisions regarding the extent of data acquisition activities [Ditmars, 1988].

Models of remedial actions are becoming essential elements in the decision process. Hydraulic control of contaminated groundwater throughout pump-and-treat systems has been modeled creatively in an attempt to optimize the cleanup [Ahlfeld, 1988] and to demonstrate the effects of alternative solutions to the stakeholders. Advanced visualization systems now allow modelers to provide easily generated multiple three-dimensional views of groundwater contaminant transport during the model application to remedial decision makers [Williams and Durham, 1992]. These visualization tools were used to demonstrate the efficacy of soil vapor extraction systems [Shikaze et al., 1993]. Advanced graphics also permit rapid observation of whether predictions will satisfy remedial goals [Sepehr and Samani, 1993]. 


\section{Conclusions}

The slow pace of cleanup and the realities of the resource and time expenditures have caused a re-examination of the process that leads to cleanup. New decision strategies have been developed that attempt to link closely the decisions and the information on which they depend. The realizations that uncertainty cannot be eliminated by sampling and that a finite risk is associated with all decisions are embedded in these strategies. Technologies for sampling, chemical analysis, and data integration are essential to implementing this new approach. While several such technologies are presently employed, the challenge remains to develop and utilize technologies that will continue to improve the decision making that leads to cleanup.

\section{Acknowledgments}

This work was supported by the U.S. Department of Energy, Assistant Secretary for Environmental Managment, under contract W-31-109-Eng-38. 


\section{References}

Ahlfeld, D.P., J.M. Mulvey, G.F. Pinder, and E.F. Wood. 1988. Contaminated Groundwater Remediation Design Using Simulation, Optimization, and Sensitivity Theory, 1. Model Development. Water Resources Research 24(3): 431-441.

Bratton, J.L., W.L. Bratton, and J.D. Shinn. 1993. In-Situ Laser Induced Fluorescence. In Proceedings on 19th Environmental Symposium \& Exhibition, American Defense Preparedness Association. Albuquerque, NM. March 22-25. pp. 26-81.

Burton, J.C. 1992. Prioritization to Limit Sampling and Drilling in Site Investigations. In Proceedings Federal Environmental Restoration Conference \& Exhibition. Vienna, VA. April 15-17. pp. 242-251.

Cherry, A., J.J. Walsh, G.D. Towson, and J.P. Handley. 1992. Rapid Aquifer Characterization of a Hexavalent Chromium Plume Using Direct Push Technology and Field Chemical Analysis. In Proceedings of Hazardous Materials Control/Superfund '92. Washington, D.C. December 1-3. pp. 207-213.

Ditmars, J.D. 1988. A Method for Evaluating the Effectiveness of Site Characterization Measurements. In Land Disposal of Hazardous Waste: Engineering and Environmental Issues. J.R. Gronow, A.N. Schofield, and R.K. Jain, eds. John Wiley \& Sons, New York. pp. 59-68.

EPA, Environmental Protection Agency. 1993. Data Quality Objectives Process for Superfund. Interim Final, EPA-540-G-93-071, Washington, D.C. September.

Freeze, R.A., J. Massmann, L. Smith, T. Sperling, and B. James. 1992. Hydrogeological Decision Analysis, National Ground Water Association, Dublin, $\mathrm{OH}$.

GAO, United States General Accounting Office. 1992. Superfund: Problems with the Completeness and Consistency of Site Cleanup Plans. GAO/RCED-92-138. Washington D.C. May

Gianti, S., R. Dailey, K. Hull, and J. Smyth. 1993. The Streamlined Approach for Environmental Restoration. In Proceedings of Waste Management '93. Tucson, AZ. February 28-March 4. pp. 585-587.

Huber, M. 1994. Multimedia Enhances GIS Applications. GIS World 7(8): 51-52.

Hyndman, D.W., J.M. Harris, and S.M. Gorelick. 1994. Coupled Seismic and Tracer Test Inversion for Aquifer Property Characterization. Water Resources Research 30(7): 1965-1977.

Jenkins, T.F. and M.E. Walsh. 1992. Development of Field Screening Methods for TNT, RDX and 2,4-DNT in Soil. Talenta 39(4): 419-428.

Johnson, R.L. 1993a. A Bayesian Approach to Contaminant Plume Delineation. In Proceedings 1993 Ground Water Modeling Conference. Colorado School of Mines, Golden, CO. June 9-12. pp. P-87-P-95.

Johnson, R.L. 1993b. Adaptive Sampling Program Support for Expedited Site Characterization. In Proceedings ER '93 Meeting the Challenge, Environmental Remediation Conference. Augusta, GA. October 24-28. pp. 781-787. 
Mapes, J.P., T.N. Stewart, K.D. McKenzie, L. McClelland, R.L. Mudd, W.B. Manning, W.B. Studabaker, and S.B. Friedman. 1991. PCB-RISc - An On-Site Immunoassay for Detecting PCBs in Soil. In Proceedings Hazardous Materials Control/Superfund '91. Washington, D.C. December 3-5. pp. 437-440.

McDonald, W.C., M.D. Erickson, B.M. Abraham, and A.B. Robbat, Jr. 1994. Developments and Applications of Field Mass Spectrometers. Environmental Science and Technology 28(7): 336A343A.

McGrath, L.A. and S. Brown. 1991. The Virtual Site as a Tool for Remediation Using the Observational Method. In Proceedings Hazardous Materials Control/Superfund ' 91. Washington, D.C. December 3-5. pp. 93-96.

McLaughlin, D., L.B. Reid, S.-G. Li, and J. Hyman. 1993. A Stochastic Method for Characterizing Ground-Water Contamination. Ground Water 31(2): 237-249.

Moore, J. Jr. 1994. Barriers to Technology Adoption Using Field Analytical Instruments as an Example. Environmental Science and Technology 28(4): 193A-195A.

Neptune, M.D., E.P. Brantly, M.J. Messner, and D.I. Michael. 1990. Quantitative Decision Making in Superfund: A Data Quality Objectives Case Study. Hazardous Materials Control 3(3): 19-27.

Prochaska, K., J. Hartness, and L. Janis. 1991. Rapid Delineation of a Chlorinated Solvent Plume Using a Hydro Punch and Field GC. In Proceedings Hazardous Material Control/Superfund '91. Washington, D.C., December 3-5. pp. 54-57.

Rafai, H.S. 1994. Decision Support Systems in the Public Domain: Issues and Considerations. In Proceedings EPA Decision Support Tools Workshop. Seattle, WA. June 28-29. pp. 15-17.

Roffman, A., E.J. Verbanic, and R.P. Sherrill. 1993. A Dynamic Methodology for Estimating Cleanup Efforts for Mercury in Soil at Gas Utility Gate Stations. Remediation 3(3): 413-424.

Ryti, R.T. and D. Neptune. 1991. Planning Issues for Superfund Site Remediation. Hazardous Materials Control 4(1): 47-53.

Sepehr, M. and Z.A. Samani. 1993. In Situ Soil Remediation Using Vapor Extraction Wells, Development and Testing of a Three-Dimensional Finite-Difference Model. Ground Water 31(3): 425-436.

Shikaze, S.G., E.A. Sudicky, and C.A. Mendoza. 1994. Simulation of Dense Vapor Migration in Discretely Fractured Geologic Media. Water Resources Research 30(7): 1993-2009.

Sieminski, P.E., R.M. Griswold, W.A. Koski, and J.M. Mosher. 1993. Accelerated Cleanup: A Case Study of the Streamlined Remedial Project. In Proceedings on 19th Environmental Symposium \& Exhibition, American Defense Preparedness Association. Albuquerque, NM. March 22-25. pp. 64-69.

Smyth, J.D., J.P. Amaya, and M. Peffers. 1992. Observational Approach Implementation at DOE Facilities. Federal Facilities Environmental Journal, 3(Autumn): 345-355.

Wallace, W.A. and D.R. Lincoln. 1989. How Scientists Make Decisions About Ground Water and Soil Remediation. In Proceedings National Research Council Water Science and Technology Board Colloquium. Washington, D.C. April 20-21. pp. 151-165. 
Wang, P.W., C.B. Purdy, A.N. Tardiff, E.M. Lightner, and E.A. Stallings. 1994. Characterization, Monitoring, and Sensor Technology Integrated Program: An Overview of Emerging Technologies in Site/Waste Characterization and Waste Treatment Monitoring. In Proceedings of Waste Management '94. Tucson, AZ. February 27-March 3. pp. 1085-1088.

Widdowson, M.A., C.K. Suddeth, and D.M. Scaturo. 1994. Cost-Effective Contaminant Plume Delineation Using Multilevel Drive Point Samplers. Remediation 4(1): 59-76.

Williams, G. and L. Durham. 1992. Efficient Analysis Using Custom Interactive Visualization Tools at a Superfund Site. In Proceedings Hazardous Materials Control/Superfund '92. Washington, D.C. December 1-3. pp. 1060-1072.

Woodside, G.D. and L. Otis. 1991. Use of a GIS Database in the Whitter Narrows Operable Unit Feasibility Study. In Proceedings Hazardous Materials Control/Superfund '91. Washington, D.C. December 3-5. pp. 131-135.

\section{DISCLAIMER}

This report was prepared as an account of work sponsored by an agency of the United States Government. Neither the United States Government nor any agency thereof, nor any of their employees, makes any warranty, express or implied, or assumes any legal liability or responsibility for the accuracy, completeness, or usefulness of any information, apparatus, product, or process disclosed, or represents that its use would not infringe privately owned rights. Reference herein to any specific commercial product, process, or service by trade name, trademark, manufacturer, or otherwise does not necessarily constitute or imply its endorsement, recommendation, or favoring by the United States Government or any agency thereof. The views and opinions of authors expressed herein do not necessarily state or reflect those of the United States Government or any agency thereof. 